\title{
Actitudes ante los impuestos en Roma. Aceptación, resignación y rechazo
}

\author{
The attitudes towards Roman taxes. Acceptation, resignation, \\ and rejection
}

\author{
José Carlos Jordán Reyes*
}

\begin{abstract}
RESUMEN
Las actitudes de los contribuyentes romanos ante los impuestos no fue siempre la misma. Variaron en función de

la naturaleza de cada tributo, de los procedimientos recaudatorios de cada momento y lugar y de las circunstancias personales del contribuyente. El tributo en cuanto tal no siempre generó rechazo. $A$ veces fue asumido como una contrapartida lógica del derecho de

ciudadanía y a veces incluso era autoimpuesto voluntariamente. A su vez, el rechazo a los tributos se manifestaba de muy diversos modos -la evasión

fiscal, la búsqueda del privilegio, la protesta colectiva y el recurso ante la autoridad judicial- cada uno con una gran variedad de matices.
\end{abstract}

PALABRAS CLAVE:

Tributum, evasión fiscal, protesta, privilegio, revisión judicial.

\begin{abstract}
The attitudes of Roman contributors towards taxes were not always the same. They differed depending on the nature of each tax, on the tax collection procedures, on the moment and place and the personal circunstances of tax contributors. Taxes as such were not always rejected. Sometimes they were seen as a logical counterpart of the right to citizenship and some other times they were voluntarily self-imposed. At the same time, the rejection of taxes was shown in many different ways: tax evasion, the search for privilege, collective protest, and the appeal to the judicial authorities; all of these including in turn a great variety of forms.
\end{abstract}

\section{KEYWORDS:}

Tributum, tax evasion, protest, privilege, judicial appeal.

Las actitudes de los contribuyentes ante el hecho impositivo y ante las diversas administraciones tributarias que se sucedieron y coexistieron en la larga historia de Roma, son enormemente variadas. Difieren según factores que afectan a distintos elementos constitutivos del tributo, principalmente a los siguientes:

* Centro de Trabajo: I.E.S. Mariano José de Larra. Dirección electrónica: jocajore @ gmail. com. Dirección postal: I.E.S. Maríano José de Larra. C/ Camarena, 181. 28047 Madrid. 
- El sujeto pasivo: la condición legal, el status social y económico y lo que hoy denominaríamos el domicilio fiscal del contribuyente.

- El tributo concreto de que se trate: en función de su carácter directo o indirecto ${ }^{1}$, ordinario o extraordinario, de si es susceptible de devolución o no, del tipo de gravamen, etc.

- El sujeto activo: según se trate de impuestos municipales, estatales o provinciales.

- El procedimiento recaudatorio: según lo recaude la propia Administración (republicana o imperial) o compañias de publicanos concesionarias, según el grado de coerción en la exigencia de responsabilidades en caso de mora o impago, etc.

- Según el grado de legalidad del tributo: entre las exacciones y confiscaciones de guerra y los tributos con respaldo legal hay todo un repertorio de contribuciones a mitad de camino entre la arbitrariedad y el derecho.

En el transcurso de la historia romana hay una notable evolución de la propia naturaleza jurídica del tributo. Poco o nada tienen que ver, por poner dos ejemplos extremos, el tributum cívico de la República con las liturgias municipales de la época bajo-imperial. Al igual que ocurrió con otras instituciones políticas y económicas, el tránsito de la República al Imperio exigió una adaptación de todo el edificio impositivo a las nuevas circunstancias.

\section{LA REPÚBLICA}

Si partimos en nuestro análisis de la época republicana, la principal cuestión que se nos plantea es si la obligación tributaria es una obligación implícita, consustancial con la civitas, o por el contrario es una obligación explícita. En otros términos: si el impuesto, en un sistema constitucional como el de la ciudad antigua, es una carga impuesta o consentida. La cuestión de la naturaleza coactiva o convencional del tributo puede parecer, en la práctica, irrelevante. Pero no lo es desde el momento en que esa naturaleza puede incidir, aún de forma no consciente, en las actitudes personales de los contribuyentes ante los tributos.

El ideal grecorromano era que la ciudad pudiera vivir de sus ingresos regulares, sin imponer ninguna carga financiera a los ciudadanos. Por lo menos hasta el siglo III a.C., el tipo de finanzas de Roma respondía a lo que Nicolet llama «finanzas cívicas ${ }^{2}$, que ya habían sido definidas por los tratadistas griegos como ideal opues-

1 Sin embargo, la distinción entre impuestos y tributos es inexistente para los romanos, y categorías tan básicas en la actualidad como las de impuestos directos o indirectos no tenían ningún sentido. Ni siquiera hay una separación clara entre los fenómenos fiscales y los parafiscales, entre la hacienda del Estado y la del Emperador, o, dentro de esta última, entre los bienes privados del Emperador y los adscritos al cargo.

2 C. Nicolet, Roma y la conquista del mundo mediterráneo. Vol. 1, Las estructuras de la Italia romana, Barcelona, 1982, p. 156. 
to a los despotismos orientales: con gastos reducidos, la ciudad debía mantenerse con sus propios bienes y cualquier aportación de los ciudadanos debía considerarse una especie de préstamo.

Así, la eisphora de las ciudades griegas no era una contribución permanente, por lo que era reembolsada a los contribuyentes en cuanto ello era posible. En Atenas debía ser aprobada por el pueblo y era precedida de una declaración de impunidad para el autor de la proposición. El impuesto, por tanto, era en cierto modo consentido ${ }^{3}$.

El sistema fiscal romano, en sus orígenes, no se diferencia esencialmente del que encontramos en la mayor parte de las ciudades griegas, pues obedece a la misma lógica sobre la que se sustenta la polis como forma de vida colectiva ${ }^{4}$.

En efecto, la civitas es para los romanos, igual que la polis para los griegos, una societas, un proyecto colectivo de orden moral sin otra justificación que el bien común de los miembros que la componen. Por eso los impuestos, y muy en especial los impuestos directos, se consideran como un mal necesario para la supervivencia del Estado, a los que hay que recurrir de modo excepcional. Siempre que sea posible, la ciudad debe vivir de sus propios ingresos. Los impuestos directos, sobre todo los de tipo personal, repugnan al ideal cívico, tanto griego como romano, por ser símbolo de servidumbre respecto de una potencia extranjera o de un régimen tiránico.

Los impuestos indirectos, al contrario que los directos, se aceptan en la medida en que no afectan como tales a los bienes ni a las personas de los ciudadanos, sino que vienen a ser a modo de tasas o precios públicos, es decir, la contrapartida económica por una prestación que la ciudad hace a los particulares (por ejemplo, por el uso de espacios públicos, mercados, etc.).

También se aceptan los impuestos si tienen carácter extraordinario, aún si se trata de impuestos directos: necesidades extraordinarias - sobre todo de tipo militar- requieren soluciones también extraordinarias. En estos casos se aplica el principio de que la polis es producto de un contrato implícito, en el que todo el mundo debe participar, tanto en las ganancias como en las pérdidas.

Pero fuera de estos supuestos, el ideal cívico considera el tributo como una anomalía dentro del normal funcionamiento del sistema financiero de la polis. Por eso el mundo clásico salvo, quizás, la Baja Antigüedad, desconoció la virtualidad de los impuestos como instrumento de la política económica, tal como ocurre hoy en día, y difícilmente eran posibles un plan financiero, una política fiscal y una política económica vía impuestos ${ }^{5}$. Y mucho menos una política social, puesto que la

3 Sobre las finanzas y la fiscalidad de las ciudades griegas, cf. A. Andreades, A History of Greek public Finances, 1933; M.Rostovtzeff, Historia Económica y Social del mundo Helenístico, Madrid, 1967.

${ }^{4}$ C. Nicolet, Tributum.. Recherches sur la Fiscalité Directe sous la Republique Romaine, Bonn, 1976, p. 7.

5 L.Neesen, Untersuchungen zu den direkten Staatsabgaben der Römischen Kaiserzeit, Bonn, 1980, p. 170. Diocleciano, sin embargo, utilizó al parecer conscientemente el tributum soli y el tributum 
fiscalidad romana fue, en general, regresiva ${ }^{6}$, salvo quizás durante la República y por lo que se refiere al tributum: los ciudadanos ricos pagaban más que los pobres; pero esto es porque su implicación era mayor, y porque además eran privilegiados.

El tributo, por otra parte, no presupone ningún derecho de propiedad del Estado sobre los bienes de los ciudadanos. Es más, si se considera como una participación en los gastos comunes por una necesidad extraordinaria, podía ser reembolsado - como ocurrió en Roma con el tributum en 187 a.C., cuando el botín obtenido de los gálatas permitió reembolsar una parte del tributum pagado en los años precedentes; ; o suspendido, como ocurrió entre 167 y 43 a.C., debido a que las conquistas romanas permitieron trasladar la carga fiscal de los ciudadanos a los súbditos y a los aliados de las provincias. ${ }^{8}$ Los ciudadanos, sobre todo los ricos, encontraban normal que el Estado viviera a expensas de los vencidos en la expansión imperialista de Roma, pues se consideraban los propietarios del Imperio.

En esos años se manifiesta plenamente el sentido profundo de la fiscalidad cívica grecorromana: los ciudadanos no sólo no tienen que pagar impuestos -al menos el tributum, el impuesto directo por excelencia- sino que tienen derecho a recibir del Estado alimentos y dinero. Cayo Graco llegó a decir que «es equitativo que un pueblo sin recursos encuentre en el Tesoro público un medio de subsistencia». ${ }^{9}$

\section{EL IMPERIO}

Después de la República, encontramos dos momentos históricos cruciales en la evolución del sistema impositivo romano, dos movimientos renovadores dirigidos, respectivamente, por Augusto y por Diocleciano.

El tránsito de la República al Imperio supuso un cambio radical de todo el sistema tributario. Augusto se vio impulsado por la necesidad de aumentar los ingresos públicos, necesidad derivada de un aumento exponencial de los gastos. Al considerarse abolido en la práctica el principal impuesto directo, el tributum, se hizo necesario crear nuevos impuestos.

Por otra parte, en tiempos de Augusto, el número de ciudadanos se había ampliado hasta los cinco millones, por lo que el contenido de los derechos y obligaciones de los miembros de la civitas originaria había cambiado considerablemen-

capitis para la dirección y reglamentación de la economía, a favor de la población urbana o de la recuperación económica de las provincias devastadas, o para intensificar o relajar la vinculación de los campesinos a la tierra. Cf. F.M. Heichelheim, Historia Económica y Social de Roma, Madrid, 1982, p. 180.

${ }^{6}$ K.Hopkins, «Taxes and Trade in the Roman Empire», Journal of Roman Studies, 70, 1980, p. 121.

C.Wang, "Taxation and Empire: from Cicero to Augustus», www. Stanford.edu/ chenliu/school/ ihum31brp.pdf

7 Tito Livio, XXXIX, 7, 1-2.

8 Plinio, XXXIII, 56; Cicerón, De Off., II, 76.

9 Floro, Epítome, II, $1,2$. 
te, así como los términos del contrato implícito que los mantenía unidos en un mismo cuerpo político.

En adelante, ya no serán los ricos los que sirvan en el ejército, sino los proletarios, como soldados profesionales; y estos proletarios están prácticamente exentos de los impuestos directos y de algunos indirectos. Por otra parte, los ciudadanos ricos y la clase media, prácticamente dispensados del servicio militar, pero sujetos a la vicesima hereditatum y otros tributos, están cada vez más desinteresados en participar en la vida de la ciudad, participación que, anteriormente, compensaba sus cargas financieras y personales.

Aunque el mayor peso impositivo recaía en las provincias, bajo Augusto también se hicieron reformas para aplicar un sistema tributario uniforme en toda Italia. En un primer momento se mantuvo el stipendium o decima en las provincias, pero el principio de exención de que disfrutaban las tierras itálicas propiedad de ciudadanos romanos fue desapareciendo gradualmente.

Todas estas transformaciones complicaron enormemente la percepción que se tenía de los impuestos y multiplicaron la diversidad de actitudes hacia los mismos.

Las reformas de Diocleciano fueron, si cabe, aún más decisivas que las de Augusto, pues marcaron toda la evolución posterior de los sistemas impositivos, tanto de Oriente como de Occidente. En el Bajo Imperio culmina la economía financiera romana clásica, lo mismo que la perfección jurídica del Derecho romano ${ }^{10}$. Los emperadores de finales del siglo III, para evitar el colapso económico, habían presionado a sus súbditos con arbitrarias exacciones de carácter confiscatorio, tanto en dinero como en especie. Diocleciano acabó con esta situación y creó un nuevo impuesto directo -iugatio o capitatio- para cuyo cobro hizo un nuevo censo y elaboró un nuevo sistema recaudatorio.

Sin embargo, entendemos que el Imperio no supuso una transformación completa de la naturaleza jurídica de la obligación tributaria. El tránsito de la República al Principado y de éste al Dominado alteró e hizo más complejas las relaciones entre el Estado y los súbditos, pero en general todo ese conjunto de instituciones, reglas, prácticas, excepciones, tradiciones e innovaciones fiscales, visto en el largo plazo, presenta una continuidad, una íntima coherencia, un cierto carácter sistemático, no siempre fácil de delinear, que atraviesa toda la historia de Roma.

No obstante lo anterior, es innegable que durante el Imperio la percepción del hecho impositivo se transforma, dejando de considerarse un deber cívico para convertirse en una carga a veces difícil de aceptar. Consecuencia de ello es la renuencia del contribuyente a pagar y, en correspondencia, el endurecimiento de los procedimientos de apremio para hacer efectivo el cobro de cualquier deuda debida al Estado y no pagada, ya se tratara de impuestos, requisas, ventas forzosas, servicios personales, etc.

\footnotetext{
10 F.M. Heichelheim, Historia Económica y Social de Roma, Madrid, 1982, p. 174 ss.
} 
Estos procedimientos eran, en el mundo antiguo, enormemente expeditivos. En el ámbito civil romano, el deudor respondía no sólo con sus bienes, sino también con su propia persona ${ }^{11}$. La prisión y la tortura eran medios habituales utilizados para vencer la mala voluntad de los deudores y contribuyentes remisos.

Augusto introdujo una mejora al permitir sustituir la ejecución personal del deudor por la cesión de su patrimonio al acreedor (cessio bonorum). En realidad, Augusto se limitó a simplificar el procedimiento previsto en la lex Poetelia de 326 a.C. En principio, este privilegio era exclusivo de los ciudadanos romanos, pero con el tiempo fue extendiéndose a los provinciales. Sin embargo, no sirvió de gran cosa porque en la práctica esta medida no tuvo mucha aplicación.

En la segunda mitad del siglo II d.C., se dio un nuevo giro en el procedimiento recaudatorio al extenderse la responsabilidad de los individuos a los grupos familiares, vecinales o corporativos a los que pertenecían. Los magistrados municipales y los senados urbanos eran los responsables de distribuir las cargas entre los habitantes del distrito. Por supuesto, los miembros de las clases dirigentes se las arreglaron para repercutir esta carga sobre los campesinos.

A pesar de todo ello, durante el Imperio encontramos formas impositivas no sólo consentidas, sino autoimpuestas por el contribuyente mismo. Es el caso de la adiectio o ampliatio. La summa legitima o summa honoraria es, en su origen, la contribución, legalmente estipulada, que los magistrados elegidos habían de hacer a favor de la ciudad, y que normalmente se empleaban en financiar juegos, aunque también se podían destinar a la construcción de edificios públicos o, incluso, no destinarse a ningún fin concreto. Pues bien, la adiectio o ampliatio es la cantidad en que los obligados a pagar la summa legitima incrementaban ésta voluntariamente. No cabe duda de que un impuesto en el que, con frecuencia, se paga una suma superior a la que el contribuyente está legalmente obligado, es un impuesto que escapa a la lógica del tributo entendido en sentido estricto.

El fenómeno de la adiectio se puede explicar como una consecuencia de la prosperidad económica y del afán de emulación y de competencia propio de las nuevas élites urbanas durante el alto Imperio ${ }^{12}$. Pero cabe también entender este tipo de contribución como una reminiscencia del evergetismo propio de las finanzas cívicas de la polis antigua, en la que, como hemos visto, se da una cierta identidad entre el sujeto activo y el sujeto pasivo de los tributos. Y también cabe relacionarlo, por último, con el deseo de aceptación social y el sentimiento de autoestima propio de una clase social emergente.

11 El derecho romano establecía una acción personal contra los deudores condenados por sentencia judicial, la legis actio per manus iniectioniem. Si el deudor condenado no pagaba, podía ser llevado al magistrado, que lo entregaba al acreedor, en cuyo poder quedaba durante sesenta días, tras los cuales era expuesto públicamente por si alguien pagaba el rescate. De no ser así, el acreedor podía matarlo, despedazarlo — si eran varios los acreedores-o venderlo trans Tiberim. La lex Poetelia Papiria de 326 a.C. abolió este régimen inhumano, así como la prisión por deudas. Cf. J. Iglesias, op. Cit., p. 224. Augusto completó la lex Poetelia mediante la lex lulia de bonis cedendis, aunque ni una ni otra acabaron con la práctica de la coacción personal de los deudores.

12 P. Garnsey, «Taxatio and Pollicitatio in Roman Africa», Journal of Roman Studies, 61, 1971, p. 117. 
Sin embargo, y a pesar de ésta y otras figuras impositivas similares, la actitud normal ante los impuestos era muy diferente. ¿Y qué podían hacer los contribuyentes descontentos?

En el mundo antiguo y, en general, en los sistemas fiscales anteriores a la aparición de los Estados constitucionales modernos, los únicos mecanismos de que disponen para oponerse al pago de impuestos son de tipo informal: básicamente, la pura y simple evasión fiscal y, cuando ello no es posible y la presión fiscal alcanza el nivel suficiente, la protesta colectiva.

Pero también caben otros procedimientos para escapar del tributo o, por lo menos, hacerlo más soportable. Son procedimientos graciables, cuya concesión queda al arbitrio de los poderes públicos. Son, fundamentalmente: el aplazamiento el pago, la reducción de la deuda tributaria, la condonación y la exención.

En Roma existía además un procedimiento formalizado, de tipo jurisdiccional, por el que el contribuyente que viera lesionados sus derechos podía recurrir a los tribunales ordinarios de justicia y plantear un proceso contra el Estado. El fisco podía, análogamente, personarse como parte en los procesos civiles en los que considerase podía tener un interés legítimo. Sin embargo, no existía un procedimiento tributario específico.

\section{LA EVASIÓN FISCAL}

La evasión fiscal es quizás la forma más elemental de eludir el pago de un tributo. Evidentemente no carece de riesgos, pues la legislación romana y, sobre todo, la actuación de los recaudadores y agentes del Estado era, por la vía de los hechos, tremendamente expeditiva, según hemos visto. La evasión puede hacerse de diversas maneras:

1) Ocultando el hecho imponible. Por ejemplo, no declarando mercancías sujetas al portorium en las aduanas o introduciéndolas de contrabando. En general, la tarifa aduanera no era excesiva, pero las múltiples imposiciones que recaían sobre las mercancías que atravesaban varias circunscripciones, además de los peajes municipales, hicieron del portorium un tributo muy impopular que, por otra parte, entorpeció notablemente el comercio romano.

2) Falseando algún elemento objetivo o subjetivo del tributo. Por ejemplo, declarando una renta inferior a la realmente obtenida. Por lo que se refiere a los impuestos directos, el catastro establecía unas presunciones legales para la valoración de las propiedades agrícolas que hacían muy difícil el fraude fiscal.

También para la lustralis collatio ${ }^{13}$ parecen haberse establecido determinadas presunciones legales en orden a la liquidación de este tributo. Los pequeños

${ }^{13}$ Era un impuesto que gravaba los beneficios de los negotiatores, es decir, artesanos y comerciantes de cualquier tipo. La cuota del impuesto era el 2 por ciento de los beneficios obtenidos por el con- 
artesanos rurales, como alfareros y herreros, que vendían directamente sus productos estaban exentos, pero los comerciantes que traficaban con estos mismos artículos estaban sujetos al impuesto ${ }^{14}$. El número de disposiciones que prohiben la exención demuestra que muchos contribuyentes pretendían acogerse a ella, así como la dificultad de los recaudadores de determinar quién estaba sujeto y quién no. En ocasiones debía ser muy difícil determinar en cada caso quién vendía sus propios productos y quién traficaba con mercancías compradas a los productores. No sabemos cómo actuarían en estos casos los recaudadores, pero, como hemos dicho, cabe conjeturar que se aplicaban presunciones legales favorables a la hacienda pública y se forzaba a pagar.

También podían ocultarse ciertas circunstancias subjetivas de relevancia fiscal, como la edad, el estado civil o el domicilio del contribuyente. El status civitatis era difícilmente falseable, pero quizás no tanto la edad del contribuyente. Por ejemplo, en Siria pagaban el tributum capitis los varones desde los catorce años y las mujeres desde los doce y en ambos casos hasta los sesenta y $\operatorname{cinco}^{15}$. Cabe pensar que el falseamiento de la edad fuera un modo frecuente de evasión fiscal.

3) Mediante el fraude de ley. Por ejemplo, alterando la titularidad de los bienes o actuando en algún negocio jurídico mediante persona interpuesta. Prueba de la frecuencia de este modo de evasión fiscal es que la jurisprudencia declara nulas cualesquiera transmisiones patrimoniales, no sólo la donaciones, hechas en fraude del fisco, y también las manumisiones hechas con el mismo propósito por deudores del fisco ${ }^{16}$.

4) Mediante la traslación de la carga tributaria a otras personas. Por ejemplo, haciendo que el propio esclavo asumiera de su peculio el pago de la vicesima que el dueño estaba obligado a tributar por su manumisión. O que el comprador del esclavo cargase, en el precio, con la quinta et vicesima venalium mancipiorum que correspondía pagar al vendedor. Lógicamente, todos los impuestos indirectos al consumo acababan recayendo sobre el consumidor final.

Otra forma de traslación de la obligación tributaria la encontramos en las cargas municipales, que los senados locales hacían por repercutir sobre los campesinos dependientes.

La traslación también podía hacerse de oficio, como cuando se establecía la garantía personal y patrimonial del recaudador en caso de incumplimiento por parte de los sujetos pasivos.

\footnotetext{
tribuyente en el ejercicio de su actividad empresarial. La base imponible se calculaba valorando los factores de producción, tales como las herramientas, o las existencias de mercancías para la venta, y también los bienes adquiridos por el sujeto pasivo, durante un quinquenio, en el ejercicio de su actividad o profesión. Se trata, por tanto, de un impuesto en parte sobre el capital, en parte sobre los bebeficios, y cuya cuota se basaba en presunciones.

14 Código Teodosiano, XIII, 1, 10.

15 Digesto, 50, 15.

16 Digesto, 49, 14, 45.
} 
5) Situándose al margen de la ley y de la sociedad mediante un acto de suicidio civil, como es huir del domicilio para no ser hallado por los recaudadores. Es el procedimiento más extremo que cabe pensar, pero no faltan referencias históricas. Su consecuencia última y más lógica es el bandolerismo. Bajo el emperador Cómodo, el número de fugitivos que se refugiaban en las zonas pantanosas del Delta del Nilo para escapar a las levas forzosas, a las prestaciones personales y a los impuestos era tan elevado que, agrupados en cuadrilla y bajo el mando de un sacerdote, llegaron a poner en jaque al gobierno provincial ${ }^{17}$.

Durante el bajo Imperio no fueron infrecuentes estas formas de marginación, voluntaria o inducida, aunque muchas veces es difícil separar las causas puramente fiscales de las que tienen su origen en la situación de crisis generalizada que se vivió en el Imperio a partir del siglo III d.C.

\section{LA PROTESTA}

La protesta es la forma más elemental de oponerse colectivamente a la aplicación de un tributo, y en ella caben diferentes grados de intensidad.

En la historia de Roma tenemos episodios muy numerosos de protestas colectivas contra los tributos, a pesar de que la presión fiscal en Roma fue, durante una buena parte de su dilatada historia, relativamente moderada ${ }^{18}$. K. Hopkins ha calculado que la tasa de imposición durante el Alto Imperio era inferior al $10 \%$ del producto total de su economía ${ }^{19}$, lo que sitúa a la presión fiscal romana de esta época en niveles muy bajos en comparación con otros períodos históricos ${ }^{20}$.

A la hora de estudiar las protestas contra los tributos hay que distinguir, una vez más, entre el tributum y las demás imposiciones, tanto fiscales como parafiscales $^{21}$.

1) Ya hemos visto cómo el tributum es la expresión de una fiscalidad cívica, republicana, en la que los sujetos activo y pasivo de la obligación tributaria se confunden, al menos conceptualmente. Las protestas contra este impuesto debieron ser muy raras, habida cuenta de la presión moral ejercida por las estructuras cívicas y de su fuerte progresividad ${ }^{22}$. El tributum es indictum, es decir, decidido -bajo decreto del Senado- por un magistrado, asimilado a un acto del magistrado. Entra en la esfera de la potestas. Contra este edictum sólo cabía un procedimiento de

17 Dión Casio, 72, 4, 1, ss.

18 K. Hopkins, «Taxes and Trade in the Roman Empire (200 B.C.-A.D. 400)», Journal of Roman Studies, 70, 1980, pp. 116 ss. M. Rostovtzeff precisa que los impuestos directos eran, en general, moderados. Cf. Op. cit.2, p. 218.

19 Ibid., p. 119.

20 La tasa, sin embargo ya se había triplicado en tiempos de Justiniano. Cf. A.H.M. Jones, The Roman Economy, Nueva Jersey, 1974, p. 161.

21 Ingresos parafiscales son aquellos que, sin ser tributos en el sentido propio, se integran en el sistema fiscal como figuras adicionales o superpuestas al mismo.

22 C. Nicolet, Op. cit. 2, p. 65. 
derecho: el recurso contra la acción arbitraria del magistrado, es decir, el recurso a los tribunos de la plebe.

2) Mucha más importancia tuvieron las protestas de los provinciales a finales de la época republicana, debido sobre todo a los abusos de las compañías de publicanos. Muy conocida es la actuación de Verres en Sicilia. Cuando fue pretor de la provincia, permitió que los publicanos concesionarios de la recaudación del diezmo obtuvieran pingües beneficios mediante prácticas ilegales: cobrando varias veces el tributo a las mismas personas, o exigiendo cantidades muy superiores a las autorizadas ${ }^{23}$.

Prueba del descontento por estos abusos es el hecho de que los publicanos necesitaran el auxilio del ejército para realizar su función. Y cómo, a comienzos del siglo I a.C., la presión fiscal en Asia era tan grande que el legado proconsular, Publio Rutilio Rufo, tuvo que tomar cartas en el asunto para evitar una sublevación de la provincia ${ }^{24}$.

Hay que señalar, no obstante, que estas protestas se debían, más que a una elevada tasa de imposición, a la corrupción y el abuso generalizados que conllevó el sistema de arriendo a las compañías de publicanos. Buena prueba de ello es que si la actuación de éstos se hacía conforme a derecho, no sólo no había protestas sino que se producían muestras de agradecimiento, como ocurrió con la actuación del padre de Vespasiano en Asia y por la que los provinciales, agradecidos, le erigieron estatuas y estelas ${ }^{25}$.

El Principado, en general, trajo consigo una mejora de la situación para la mayor parte de los contribuyentes. Hubo protestas, por descontado. Nerón pretendió abolir los impuestos indirectos a causa de las protestas populares, aunque al final no lo hizo ${ }^{26}$. Tácito señala que Judea y Siria, «exhaustas por los impuestos, imploraron a Tiberio la reducción del tributo" (Anales, II, 42). Sin embargo, como señala Wang, el hecho de que las provincias eligieran un modo diplomático en lugar de recurrir a métodos violentos, indica una razonable presión fiscal bajo el Principado ${ }^{27}$.

A partir de Adriano, con el cese de la expansión imperial romana, las necesidades financieras crecientes del Imperio llevaron a la extensión del sistema de liturgias, mediante el cuál las clases urbanas ricas se hacían responsables de las obligaciones fiscales de los pobres. De la dureza de estas obligaciones es buena prueba la serie de revueltas que estallaron en tiempos de Marco Aurelio y, sobre todo, los sucesos que se produjeron en Alejandría en tiempos de Caracalla. Antes de su expedición contra los partos, éste hizo asesinar, sin causa aparente, a toda la juventud alejandrina y a los ciudadanos en cuyas casas se alojaban sus solda-

23 Cicerón, Verrinas, 2, 1, 49, 129.

24 Diodoro, 37, 5, 1-4.; Dion Casio, 28, 97.

25 Suetonio, Vespasiano, 1, 3.

26 M. Rostovtzeff, Op. cit. 2, vol. II, p. 218.

27 C. Wang, Op. cit., p. 10. 
dos y oficiales. Rostovtzeff sostiene que toda la carga económica de la campaña recayó sobre Egipto, y que el malestar debía ser tan grande que el emperador temió una insurrección tan pronto se encontrara en Partia. Para evitarla, ordenó esta terrible represión. En cualquier caso, el malestar debía ser real porque por estos mismos años se difundió por toda la provincia un libelo contra Caracalla conocido como las «Actas de los mártires paganos» ${ }^{28}$.

\section{EL PRIVILEGIO}

Sin embargo, y a pesar de estos episodios, ya desde la época de los Antoninos comenzamos a encontrar, con mucha más frecuencia que antes, otro medio para eludir las obligaciones fiscales de las ciudades o de ciertas corporaciones: la obtención de privilegios, tales como exenciones, aplazamientos, reducciones de impuestos y la condonación de deudas tributarias atrasadas.

No hay que infravalorar la importancia económica de estas medidas de gracia: se ha señalado que eran, después del ejército, la segunda partida más importante de los gastos del Estado durante el Alto Imperio. Aunque en la misma partida se incluyen también la annona y otras concesiones gratuitas a los ciudadanos de Roma, el dato no deja de resultar impresionante ${ }^{29}$.

Tampoco hay que pensar que eran medidas excepcionales: Adriano y Marco Aurelio combinaron la concesión de estas mercedes con una mayor intervención en la gestión financiera de las ciudades ${ }^{30}$.

La concesión de estos privilegios y exenciones quizás no empeoraba la situación del fisco, aunque desde luego tampoco la mejoraba. Podemos decir que era una válvula de escape selectiva al descontento. Lo que hacían, en el fondo, era endurecer las condiciones de quienes no eran capaces de obtener los privilegios, que habían de contribuir doblemente: por sí mismos y por los que disfrutaban de aquéllos. En la clásica competencia entre los distintos agentes, clases o grupos sociales por obtener ventajas del Estado, unos ganan y otros pierden, pero la suma total de pérdidas y ganancias es necesariamente cero.

Con Septimio Severo el sistema de liturgias se convirtió en una institución permanente, legalizada, regulada e impuesta coactivamente por el Estado. Fue probablemente este emperador el que fijó como regla la responsabilidad personal de los magistrados municipales. Él y sus sucesores aumentaron asimismo la presión sobre las asociaciones y corporaciones que servían al Estado. Pero, al mismo tiempo, los Severos extendieron el régimen de concesiones de privilegios tanto a ciudades y corporaciones como a grupos de contribuyentes humildes.

28 M. Rostovtzeff, Op. cit. 2, vol II, p. 275.

29 F. M. Heichelheim, Op. cit., p. 126 ss.

30 Una pequeña desgravación otorgada por Marco Aurelio sobre el impuesto que gravaba los espectáculos de gladiadores fue saludada con alborozo por un senador de origen provincial. Cf. M. Rostovtzeff, op. cit. 2, vol. II, p. 222. 
1) Por lo que se refiere a las exenciones, los pequeños arrendatarios de las propiedades del emperador quedaron exentos de las liturgias municipales, aunque no de los trabajos obligatorios que eventualmente pudiera imponerles el Esta$\mathrm{do}^{31}$.

También quedaron exentos de las cargas municipales, bajo Septimio Severo, los miembros de las corporaciones que realizaran trabajos manuales indispensables para los servicios públicos, como los fabri y los centonarii, encargados de la extinción de incendios.

Aparte de las ciudades y corporaciones que disfrutaban de exenciones por concesión graciosa del emperador, existía un régimen de exenciones de las cargas municipales de tipo personal, regulado por las leyes. Este tipo de exención legal no se presumía, y la carga de la prueba correspondía a quien la alegase en el correspondiente juicio declarativo: "Toda causa tiene su justificación, pero si se creyera, sin intervención judicial, a todos los que pretenden alguna causa de excusa, o sin determinación de plazo se permitiera siempre excusarse a quien quisiera, no quedarían personas para los servicios que son necesarios en las ciudades.» (Digesto, 50, 5, 1).

Las principales causas legales de exención de estas cargas son: la edad, el número de hijos, los méritos militares, la debilidad corporal y el ejercicio de determinados oficios (maestros de escuela, publicanos, filósofos). Pero se establece una clara diferencia entre las cargas personales y las patrimoniales, de modo que el régimen legal varía en uno y otro caso.

Determinados impuestos indirectos, como los portoria, establecían también un amplio régimen legal de exenciones, tanto subjetivas como objetivas: Estaban exentos los embajadores extranjeros, el fisco, la familia imperial, los veteranos, el material militar, los instrumentos agrícolas, el material de transporte, etc.

2) Otra forma de eludir el pago de impuestos, que encontramos atestiguada en las provincias orientales del Imperio, es la adopción de ciudadanías distintas de las de origen por ser, fiscalmente, menos onerosas. Más que un privilegio, se trataría técnicamente de un caso de fraude de ley, aunque tolerado en determinados casos.

En el Oriente romano era relativamente frecuente esta práctica, y las autoridades romanas hubieron de limitarla en defensa de los derechos del fisco. La práctica de vender la ciudadanía a extranjeros ricos está atestiguada en Atenas hasta que Augusto la prohibió en el año $21^{32}$. En Tarso la ciudadanía se compra por 500 denarios a comienzos del siglo $\|^{33}$. Las restricciones a esta práctica fueron raras. En Bitinia, la Lex Pompeia prohibía la concesión de la ciudadanía a los ciudadanos

31 El Derecho romano distinguía entre las cargas municipales de tipo personal y las de tipo patrimonial. Las primeras son aquellas que requieren formalmente un esfuerzo físico con aplicación intelectual y diligencia; las segundas son aquellas en las que se exige principalmente un gasto (Digesto, 50, 4, 1).

32 Dion Casio, 54. 7. 2.

33 Dion de Prusa, XXXIV, 23. 
de las ciudades vecinas con objeto de evitar que algunos de ellos pudiesen eludir sus responsabilidades en su ciudad de origen para asumir otras menos gravosas en otra ciudad, pero en la época del gobierno de Plinio el Joven esta disposición había caido en desuso ${ }^{34}$. En Tiras, ciudad al oeste del Ponto, la ciudadanía no se vendía pero se concedía con gran facilidad. En estas condiciones, cuando la ciudad intentó conseguir ciertas inmunidades fiscales para sus ciudadanos, el emperador exigió que las concesiones de ciudadanía fuesen sometidas al gobernador. A las ciudades les interesaba incrementar el número de ciudadanos susceptibles de ocupar cargos de responsabilidad y de financiar sus necesidades, pero ello no debía perjudicar al fisco imperial.

En Egipto, Roma supervisa estrechamente las concesiones de ciudadanía. La ciudadanía de Alejandría es un privilegio otorgado por el propio emperador, pues tenía ventajas fiscales importantes, dado que los ciudadanos de las ciudades griegas de Egipto -igual que los ciudadanos romanos- escapaban a la iaographía.

3) La condonación de deudas fiscales atrasadas también está atestiguada en las fuentes. Tiberio perdonó a Sardes las deudas "aerario aut fisco» ${ }^{35}$. Adriano perdonó «infinitam pecuniam quae fisco debebatur privatis debitoribus» ${ }^{36}$. Dion Casio también menciona remisión de deudas tanto al fisco como al aerarium ${ }^{37}$.

La condonación de deudas no supone, como la exención, la consolidación de una situación de privilegio, sino un acto de gracia que se agota en sí mismo y no altera la relación jurídica existente.

4) Por lo que se refiere al aplazamiento del pago, el Digesto establece, al arbitrio del juez, una moratoria de dos meses para el pago de deudas tributarias menores, y de tres meses para cantidades mayores. Prórrogas por tiempo superior a los tres meses han de solicitarse al emperador ${ }^{38}$.

Sin embargo, un papiro del reinado de Cómodo, recogiendo una carta dirigida por el prefecto de Egipto a los strategoi de Tebaida, Hepta Nomoi y Arsinoe, establece que se vendan los bienes embargados por deudas fiscales si estas no eran pagadas en el plazo de seis meses ${ }^{39}$.

5) La compensación como forma de extinción de las obligaciones tributarias está expresamente excluida por la jurisprudencia. Sin embargo, sí se admite la compensación entre deudas y créditos del fisco con particulares por otros conceptos, siempre que la reclamación se haga en el plazo de dos meses ${ }^{40}$.

34 Plinio, Cartas, X, 114.

35 Tácito, Anales, II, 47, 3.

36 S.H.A., Adriano, 7, 6.

37 Historia Romana, LXIX, 8, I.

38 Digesto, 49, 14, 45.

39 Citado por F. Millar, «The Fiscus in the First Two Centuries», Journal of Roman Studies,53, 1 y 2 , 1963, p. 32.

40 Digesto, 49, 14, 46. 


\section{LA REVISIÓN JURISDICCIONAL}

Junto a estos procedimientos informales, el Derecho romano proporcionaba a los contribuyentes los mecanismos legales para obtener una revisión jurisdiccional de sus obligaciones fiscales, especialmente las relacionadas con los impuestos arrendados a compañías de publicanos.

El Digesto concede acción civil y penal contra los publicanos que hubieren arrebatado injustamente bienes, mediante violencia, en nombre del fisco. Estas acciones, además, son independientes de las que pudieran incoarse, con carácter general, por cualesquiera hurtos, robos o daños violentos. Es decir, el legislador ha pretendido ofrecer una protección especial y reforzada al contribuyente, en virtud de la peculiar condición del autor del delito ${ }^{41}$. Sin embargo, como ya se ha mencionado, no existía en el Derecho romano un procedimiento tributario como tal.

También existe una numerosa jurisprudencia relativa a los procesos en los que el fisco se persona como parte actora en defensa de sus derechos. Para un particular, verse involucrado en un pleito contra el fisco podía ser «a dangerous business ${ }^{42}$, pero lo cierto es que la jurisprudencia admite el principio de que, en controversias dudosas, es legítimo fallar en contra del interés del fisco ${ }^{43}$.

En cualquier caso, a medida que fueron aumentando las propiedades fiscales, la participación del fisco en litigios civiles y penales fue siendo cada vez más importante, como lo prueba la creación por Adriano del cargo de advocatus fisci4 ${ }^{44}$.

Con el tiempo, los privilegios procesales del fisco fueron aumentando. El Digesto dedica todo un título a tratar el tema ${ }^{45}$. Los privilegios más destacables eran el poder reclamar de terceros los bienes adquiridos de un deudor del fisco y la preferencia a la hora de cobrar sus créditos frente a otros acreedores del mismo deudor.

Al mismo tiempo, otras disposiciones garantizaban los derechos de los ciudadanos frente al fisco. Ya hemos mencionado la admisión del principio in dubio pro reo en las causas fiscales. Un rescripto de Septimio Severo y de Caracalla impide al procurador del César vender bienes mientras fueran objeto de litigio; incluso los bona damnatorum del reo de un delito de lesa majestad que hubiera fallecido, no podían ser vendidos por el fisco si el heredero del reo iniciaba acciones legales para probar su inocencia. Tampoco puede apropiarse el fisco de los bienes del suicida hasta que se pruebe que se suicidó por haber cometido un delito, pues si se suicidó por tedio de la vida, deudas o enfermedad incurable, los herederos conservan sus derechos.

41 Digesto, 39, 4, 1.

42 F. Millar, Op. cit., p. 31.

43 Digesto, 49, 14, 10.

44 S.H.A., Adriano, 20, 6.

45 Digesto, 49, 14, 1-50. 
Así pues, aunque los privilegios procesales del fisco eran numerosos, lo cierto es que estaban legalmente tasados. Es decir, que la posición legal y procesal del fisco, frente al contribuyente, estaba sujeta a derecho y por lo tanto a salvo de la arbitrariedad del poder público. Y en este sentido es poco importante el hecho, ya señalado, de que litigar contra el fisco fuera un asunto peligroso en la práctica, porque la asunción, aún en el plano teórico, del contribuyente como sujeto de derechos, eleva al sistema fiscal romano al ámbito de lo jurídico, lo que por sí mismo contrasta con el despotismo que observamos en otros ámbitos del poder imperial.

En definitiva, la visión tradicional de una fiscalidad romana sometida al terrorismo fiscal de una administración insaciable, ha de ser matizada. Es cierta la explotación inmisericorde de las provincias a finales de la república por parte de las compañías de publicanos, así como la generalización durante el imperio de arbitrarias liturgias de origen oriental. Pero la actitud de los contribuyentes hacia los impuestos no fue uniforme. El tributum no era contemplado como un tributo impuesto, siendo más bien consentido como una contrapartida necesaria por el privilegio de pertenecer al cuerpo político de la ciudad. Incluso durante el Imperio encontramos figuras tributarias autoimpuestas, como la adiectio o ampliatio, que, aunque minoritarias, mantienen un cierto nexo con la tradición cívica republicana.

Lógicamente, respecto a la mayor parte de las contribuciones fiscales y parafiscales la actitud normal fue de rechazo, en una escala que va desde la resignación al descontento más o menos explícito. La evasión fiscal, la protesta y la búsqueda del privilegio, cada una con sus diferentes fórmulas y modulaciones, son probablemente modelos universales de oposición a los tributos. Pero en la Antigüedad sólo Roma desarrolló un procedimiento jurisdiccional, formalizado y complejo, como salvaguarda ante los abusos en el ius imponendi.

\section{BIBLIOGRAFÍA}

AA.VV., Roman Civilization: Selected Readings, Berkeley, 1990.

ANDREADES, A. A History of Greek public Finances, 1933.

BALL, W. Rome in the East. The transformation of an empire, Nueva York, 2001.

BIONDI, B. Sucessione testamentaria e donazione in Roma antica, Milán, 1955.

BONELLI, G. Le imposte indirette di Roma antica, en Studi e Documenti di Storia e Diritto, 1990.

BONINI, J. Ricerche di diritto giustiniano, Milán, 1968.

BOUCHÉ LECLERCQ, A. Manuel des institutions romaines, París, 1886.

BRUNT, P. A., «The Fiscus and its Development», Journal of Roman Studies, 1966.

BRUNT, P. A., Italian Manpower. 225 B.C.- A.D. 14. Oxford, 1971.

BRUNT, P. A., Roman Imperial Themes, Oxford, 1990.

CAGNAT, R., Etude historique sur les impôts indirects chez les romains, París, 1882.

CARNEY, T. F., The Economies of Antiquity, Kansas C. P., 1973

CHEN LI WANG, «Taxation and Empire: From Cicero to Augustus.» WWW.stanford.edu/chenliw/school/ihum31brp.pdf. 5 de abril de 2005.

CIMMA, M.R., Ricerche sulle società di publicani. Milán, 1981. 
CLERICI, L., Economia e finanza dei Romani, Bolonia, 1934.

CORBIER, M., «Devaluation et fiscalité (161-235)», en Les dévaluations à Rome. Collection de l'école française de Rome, 37, 1978.

CORBIER, M.,L" Aerarium Saturni et l'Aerarium militare. Administration et prosopographie sénatoriales, Roma, 1974.

CRAWFORD, M., «Money and Exchange in the Roman World», Journal of Roman Studies, 60, 1970.

D'AMATI, N., «Natura e fondamento del tributum romano», Ann.Fac.Giur. Bari, XVI, 1962.

D'ARMS, J. H., Commerce and social standing in ancient Rome, Cambridge- Massachussetts, 1981.

DE LAET, S. J., Portorium, Brujas, 1949.

DE MARTINO, F., Historia económica de la antigua Roma, Madrid, 1979.

DE MARTINO, F., Nuovi studi di economia e diritto romano, Roma, 1988.

DE VISSCHER, F., Le droit des tombeaux romains, París, 1963.

DI PAOLA, Donatio mortis causa, Roma, 1969.

DI RENZO, F., La Finanza Antica, Nápoles, 1955.

DUNCAN-JONES, R.., The Economy of the Roman Empire. Quantitative Studies, Cambridge, 1982.

DUNCAN-JONES, R., Structure and Scale in the Roman Economy, Cambridge, 1990.

ERDKAMP, P., The Roman Army and the Economy, Amsterdam, 2002.

FALLU, E., Cicéron et las finances publiques, Paris, 1974

FERNÁNDEZ URIEL, P.,«Algunas precisiones sobre el sistema fiscal romano», Espacio, Tiempo, Forma, 1995.

FERNÁNDEZ URIEL: P., «Un fundamento en la economía de los Estados Modernos: El Sistema tributario romano. (Alto Imperio)» Aportación romana a la formación de Europa: Naciones, lenguas, culturas. Segundo coloquio de la Asociación Interdisciplinar de Estudios Romanos (AIER) 2004. (En prensa).

FINLEY, M., «The Ancient City: From Foustel de Coulanges to Max Weber and beyond», Comparative Studies in Society and History, 19.3, 1977.

FINLEY, M., The Ancient Economy, Berkeley, 1999.

FORTINA, M., «I <Praefecti Aerarii Saturni>» Rivista di Studi Classici, IX, 1961.

FRANK, T., "Augustus and the Aerarium», JRS, XXIII, 1933.

GARCETTI, A., «Aerarium e fiscus sotto Augusto. Storia di una questione in parte di nomi», Atheaeum, Studi periodici di letteratura e storia dell" Antichità, Pavia 1953.

GATTI, C., «Riflexioni suu'istituzione delle Stipendium», Acme, 1970.

GARNSEY, P., «Taxatio and Pollicitatio in Roman Africa», Journal of Roman Studies, 61, 1971.

GILLIAM, J.F., «The minimum Subject to the Viccessima Hereditatum», AJPh., 1952.

GRANT, M., The World of Rome, Londres, 1974.

GRELLE, I., "Stipendium vel tributum», Labeo, 12, 1966.

HARRIS, W. V., Guerra e imperialismo en la Roma republicana, Madrid, 1979.

HEICHELHEIM, F.M., Historia Económica y Social de Roma, Madrid, 1982.

HOMO, L., Les institutions politiques romaines de la cité à l'état, París, 1927.

HOPKINS, K., «Taxes and Trade in the Roman Empire», Journal of Roman Studies, 70, 1980.

HOWGEGO, C., «The supply ald Use of Money in the Roman World 200 B.C. to A.D. 300», Journal of Roman Studies, 82, 1992.

IGLESIAS, J., Derecho Romano. Instituciones de Derecho privado, Barcelona, 1986.

JOLOWICZ, H. F., An Historical Introduction to the Study of Roman Law, Cambridge, 1952.

JONES, A.H.M., «The Aerarium and the Fiscus», Journal of Roman Studies, 40, 1950.

JONES, A.H.M., The Roman Economy, Nueva Jersey, 1974.

LO CASCIO, E., II Princeps e il suo Impero, Roma, 2000. 
LUZZATTO, V. G. I.., La riscossione dei tributi in Roma e l'ipotesi della proprietà sovrana, Atti del Congreso di Diritto Romano di Verona, 1953.

MARQUARDT, J., De lorganisation financière chez les Romains, París, 1888.

MILLAR, F., «The Fiscus in the First Two Centuries», Journal of Roman Studies,53, 1 y 2, 1963.

MILLAR, F., The Roman East, 31 bC - aD 337. Cambridge (Mass.) y Londres, 1993.

MOMMSEN, T., Historia de Roma, 2 vols., Madrid, 2003.

MOMMSEN, T., Le droit publique romain, París, 1891.

MURGA, Derecho romano clásico. El proceso, Zaragoza, 1980.

NAQUET, H., Des impôts indirects chez les Romains sous la République et sous f Empire, París, 1879.

NARDO E. Y FALCIANI, D., II Sistema Tributario dell antica Roma. Prima parte. www.gdf.it/RIVISTA/Sitorivista/Anno\%201999/Rivista\%202-1999/ARTICOLI/18nardo.html - (2 de septiembre 2005).

NARDO E. Y FALCIANI. D., II Sistema Tributario dell'antica Roma, Seconda Parte. www.gdf.it/RIVISTA/Sitorivista/Anno\%201999/Rivista\%206-1999/ARTICOLI/ 13Nardo.html - (2 de septiembre 2005).

NEESEN, L., Untersuchungen zu den direkten Staatsabgaben der Römischen Kaiserzeit, Bonn, 1980.

NESSELHAUF, H., Patrimonium und res private des römischen Kaisers Historia Augusta Colloquium, Bonn, 1963.

NICOLET, C., Tributum. Recherches sur la Fiscalité Directe sous la Republique Romaine, Bonn, 1976.

NICOLET, C., Roma y la conquista del mundo mediterráneo. Vol. 1, Las estructuras de la Italia romana, Barcelona, 1982.

NICOLET, C., «Prosopographie et Histoire sociale: Rome et l'Italie à l'époque républicaine». Annales E.S.C. $25 .^{\circ}$ année, 1970.

NICOLET, C., Le metier de citoyen de citoyen dans la Rome Républicaine. Paris, 1976.

NICOLET, C., «L'ideologie du système centuriate et l'influence de la philosophie grecque «, Colloquio Filosofia greca e Diritto Romano, 1973, Acc. Naz. Lincei. Quaderno 221, 1976.

NICOLET, C., «Armée et Fiscalité: pour un Bilan de la Conquête romaine», Armées et Fiscalité dans le Monde Antique.CNRS, Paris, 1977.

PÉREZ DE AYALA GARCÍA PELAYO, C., Temas de Derecho Financiero, Madrid, 1988.

PETIT, P., La Paz Romana, Barcelona, 1976.

RATHBONE, D.W., «The Imperial Finances», The Cambridge Ancient History, Ed. Alan Bowman, Ed. Champlin -Andrew Lintott, Vol. X, 2 ed. Cambridge, 1996.

RIBÓ DURÁN, L., Diccionario de Derecho, Barcelona, 1987.

RODBERTUS, J. K., Per la storia delle imposte romane da Augusto in poi, Jena, 1869.

ROSTOVTZEFF, M., Historia Económica y Social del mundo Helenístico, Madrid, 1967.

ROSTOVTZEFF, M., Historia Económica y Social del Imperio Romano, Madrid, 1967.

SARTRE, M., El Oriente Romano. Provincias y Sociedades provinciales del Mediterráneo oriental, de Augusto a los Severos (31 a.C.-235 d.C.), Madrid, 1994.

SAVIGNY, Römische Steuerverfassung, 1882.

SOLER ROCH, M. T., «Notas sobre la configuración de las obligaciones y deberes tributarios», Revista Española de Derecho Financiero, 25, 1980.

SUTHERLAND, C.H.V., "Aerarium and Fiscus during the Early Empire», Journal of Philology, 66, 2, 1945.

SYME, R., «People in Pliny», JRS, LVIII, 1968.

TENNEY, F., An Economic Survey of Ancient Rome, vol. 5, Baltimore, 1940.

TENNEY, F., An Economic History of Rome, Nueva York, 1962.

VEYNE, P., La societé romaine, París, 1990.

VIGIË, I., Des douanes dans /Empire romain, París, 1884. 
WALLACE, S. L., Taxation in Egipt from Augustus to Diocletian, Princeton, 1938. WHITTAKER, C.R., Land, City and Trade in the Roman Empire, Nueva York, 1993.

WHITTAKER, C.R., " Trade and the aristocracy in the Roman Empire», International Journal for Social and Economic History of Antiquity, 4, 1988. 